\title{
MEIOS DE HOSPEDAGEM: INDICADOR DA ATIVIDADE TURÍSTICA NA TRANSFORMAÇÃO DO ESPAÇO URBANO DE FLORIANÓPOLIS
}

\author{
HOSTELRY: TOURISM INDICATOR IN THE LANDSCAPE TRANSFORMATION OF \\ FLORIANÓPOLIS
}

\author{
SANTIAGO, Alina Gonçalves \\ Arquiteta, Doutora pela Universidade de Paris - I Panthéon-Sorbonne (França), Professora adjunta do \\ Departamento de Arquitetura e Urbanismo/UFSC. Coordenadora do Grupo Infoarq. \\ E-mail: alina@arq.ufsc.br
}

ESPÍNDOLA, Luciana da Rosa

Estudante de graduação do Curso de Arquitetura e Urbanismo da Universidade Federal de Santa Catarina. Bolsista PIBIC/CNPq-UFSC no Grupo de Pesquisa da Informática na Arquitetura - INFOARQ.

E-mail: luciana.esp@ig.com.br

\section{RESUMO}

O fenômeno do turismo, como um importante articulador e indutor do consumismo nesse período da crescente globalização, gera paisagens valorizadas por empreendimentos. Provoca inúmeros impactos positivos e negativos onde se desenvolve.

município de Florianópolis transformou-se em uma importante capital turística devido o privilégio por sua localização geográfica e a existência de inúmeros ambientes naturais ricos. A espacialização dos dados relativos aos meios de hospedagem na llha de Santa Catarina, com auxilio do sistema de informação geográfica (SIG), permite compreender elementos indutores de transformação do espaço urbano na análise de uso e ocupação do solo.

Nos três anos base 1980, 1994 e 2004, mapeou-se o número total de estabelecimentos, leitos e unidades habitacionais ( $U H^{\prime}$ s) do município de Florianópolis.

Os mapas permitem análises e diagnósticos sobre a demanda turística em cada região e no município ao localizar o indicador turístico meios de hospedagem. Verificam-se as regiões sob maior demanda turística e o estágio de desenvolvimento turístico nas diversas áreas.

O fenômeno turístico gera grande número de deslocamentos e uma grande concentração de pessoas em determinados locais. Essa disseminação dos estabelecimentos em novas áreas ocasiona uma deterioração ambiental cada vez mais esparsa no território. Portanto, urgem definições de diretrizes e políticas para o desenvolvimento de um turismo sustentável para todo o município de Florianópolis.

Palavras-chave: Turismo, degradação ambiental, meios de hospedagem e sistemas de informação geográfica.

\section{ABSTRACT}

The tourism, as an important articulator and inductor of consumes in this period of growing globalization, increases valued environments by undertakings.

Florianópolis became an important touristy capital because of its privileged geographic location and the existence of many rich natural environments.

The spatially of the related data about the hostelry of Santa Catarina Island, with geographic information system (GIS) help, allows understanding inductors elements of urban space transformation in the use and occupation analyses of the landscape. In three base years: 1980, 1994 e 2004, it has been mapped the total number of establishments, beds and bedrooms of Florianópolis city.

Establishments' propagation in new areas causes a more and more spread environmental deterioration in the territory. Therefore, politics definitions for a sustain tourism development for the entire Florianópolis city are required.

Key words: Tourism, environmental degradation, hostelry, geographic information system. 


\section{Introdução}

Florianópolis, capital do Estado de Santa Catarina, localiza-se na região mediana do litoral catarinense. Seu território totaliza uma área de $452 \mathrm{~km}^{2}$, soma de uma porção insular (438 $\mathrm{km}^{2}$ ) e de uma porção continental $\left(12,1 \mathrm{~km}^{2}\right)$ (HAFERMANN, 2004). A llha e o continente juntos formam um si um sistema bem heterogêneo, com porções diferenciadas entre si, demonstrando a riqueza desta porção urbana, que conformam o município de Florianópolis.

Sua organização espacial sofre contínuos processos de transformação advindos do crescimento da cidade desde sua gênese. Uma paisagem coberta por elementos naturais e humanos, resultado de diferentes períodos de ocupação.

O privilégio por sua localização geográfica e a existência de inúmeros e ricos ambientes naturais são alguns dos aspectos que tornaram a llha de Santa Catarina uma capital turística. No entanto, uma prática turística implantada de forma desordenada torna a cidade devastada com uma rapidez temível. Assim, a diversidade e a singularidade da llha estão ameaçadas diante dessa prática vigente.

A urbanização turística, ao acompanhar o processo de industrialização, promove mais uma reordenação espacial em Florianópolis. Como outros processos capitalistas de ocupação do solo urbano, fragmenta a cidade, como uma mercadoria, onde seu solo é disputado parte por parte. Essa perversa construção da cidade em Florianópolis ocorre num processo acelerado e caótico.

O olhar social desperta para o turismo como uma resposta rápida para aumentar a riqueza da comunidade ou pessoal em um curto período de tempo. Esta busca de lucros imediatos cegam os agentes envolvidos que disseminam novos empreendimentos em áreas sensíveis ocasionando uma degradação ambiental desnecessária na llha de Santa Catarina.

\section{Espaço urbano em Florianópolis}

A morfologia urbana é produto de processos e relações intra-urbanas. Transformações aceleradas provocadas pelo desenvolvimento do capitalismo ultrapassam barreiras e definem espaço como mercadoria.

O espaço é resultado de um sistema de ações humanas no decorrer da história, sobre a paisagem. É articulado pela sociedade e, assim, aponta a dinâmica de relações vivenciadas até o momento presente. $\bigcirc$ espaço urbano denuncia a competição que mantém elos ativos entre política e produção do espaço, motivado por diversos agentes sociais.

A organização espacial em Florianópolis sofreu transformações desordenadas e aceleradas, motivadas pela contínua evolução capitalista. A alteração do sítio urbano original e a influência da dinâmica da sociedade no decorrer da história se refletem na atual configuração espacial da llha. Apresenta núcleos urbanos dispersos, representados pelo núcleo central e pelos balneários.

A urbanização turística acompanha o processo de industrialização, e, também, vem promovendo uma reordenação espacial. As transformações de cidades em produções de cenários ilusórios condizem ao marketing do espaço e confirmam sua comercialização e indução dos turistas ao consumismo.

218 A indústria do turismo produz espaços delimitados e espacialmente destinados a um determinado tipo de consumo através dos serviços do turismo. Articula a produção e o consumo do espaço. Os meios de comunicação de massa facilitam a circulação das paisagens (RODRIGUES, 1996). O marketing, na venda de imagens ideais, que na realidade se mostram ilusórias, aliena o turista quanto à imagem real do espaço. 


\section{Influência do turismo na degradação ambiental}

O turismo mais uma vez é o eixo central do debate. Como um importante articulador e indutor do consumismo nesse período da crescente globalização, gera paisagens valorizadas por empreendimentos. A natureza é o potencial e a mercadoria essencial na estruturação da paisagem para o turismo. A motivação turística é a capacidade local de atração, privilegiada pelos fatores de diversificação. Vivenciar o imaginário é o desejo de todo turista ao visitar um local.

O turismo, como nova modalidade de consumo de massa, expande com a produção de bens (infra-estrutura, construções, alimentos) e serviços (transportes, hospedagem, alimentação) que se integram para o consumo final (FALCÃO, 1996). Devido a importância da contribuição do turismo para a economia, este é examinado detidamente pelos economistas, quanto à oferta, demanda, emprego, gastos, desenvolvimento, multiplicadores e outros fatores econômicos. Todavia, esse enfoque econômico é desvantajoso quando desvia a atenção de outros fatores que o turismo também acarreta no local, como elementos ambiental, cultural, psicológico, sociológico e antropológico.

O turismo em áreas naturais pode ser considerado uma grande oportunidade para contribuir na formação da consciência ambiental. Reflexões referentes à conservação e preservação dos recursos naturais questionam o papel do homem integrado ao meio e sua qualidade de vida. $\bigcirc$ turismo pode exercer importante papel na busca da educação ambiental estimulando, através de ações que complementam o lazer, a reaproximação e a sensibilização relativa à natureza (SIQUEIRA, 2004). Um conhecimento dos recursos locais pode promover no público sentimentos em relação à natureza que estimulem uma relação adequada e interesse mútuo entre homem e ambiente.

O crescimento acelerado e desordenado da ocupação urbana na llha de Santa Catarina é um fato preocupante, principalmente do ponto de vista da degradação ambiental. Ao mesmo tempo em que os recursos naturais são suporte para obtenção de recursos econômicos através do turismo, este estimula a destruição da paisagem e do meio-ambiente (ESPÍNDOLA e SANTIAGO, 2004). Florianópolis segue um rumo que pode imediatamente esgotar seu principal atrativo, os recursos naturais. Hoje, é evidente a trama de desequilíbrio entre espaço urbano e natural, social e econômico. A qualidade de vida local está sendo comprometida. Para uma possível perpetuação da atividade turística, é necessária e urgente, uma política de conscientização e fiscalização eficiente.

\section{Meios de hospedagem}

"Com as viagens e o incremento do comércio, como conseqüência, surgem os primeiros meios de hospedagem que se caracterizavam como estabelecimentos de passagem, para um único pernoite, já que, em função das longas distâncias, colocava-se a necessidade de locais para descanso. Alguns viajantes somente contavam com a hospitalidade dos habitantes da região, pela inexistência de locais destinados ao acolhimento das pessoas que chegavam à cidade" (SANTOS, 2004, p. 08). Estruturas de apoio que possibilitam a permanência do fluxo de visitantes no lugar de destino através de serviços de acomodações.

No passado, com as guerras e as viagens comerciais, as pessoas efetuavam deslocamentos constantes entre os locais de seu interesse. Para o abrigo noturno, estas pessoas refugiavam-se em mosteiros e abadias (para os guerreiros), ou ainda palácios e castelos (para a nobreza). Após a Primeira e Segunda Guerra Mundial, a atividade hoteleira tomou impulso, aliada ao avanço tecnológico e popularização do automóvel e crescimento do transporte aéreo. No Brasil este despertar ocorre com o surto industrial na década de 60, com a iniciativa de redes internacionais. 
Na llha de Santa Catarina, depois da Independência, o Palácio era, freqüentemente, utilizado para hospedagem e para realização de bailes para pessoas ilustres. Até mesmo o Imperador hospedou-se no palácio em 1845, e mais tarde, outros hóspedes ilustres. Em 1811, não havia em Desterro hotéis e nem hospedarias (CABRAL, 1979 apud SANTOS, 2004).

Com o crescimento e desenvolvimento urbano de Florianópolis, a indústria hoteleira começa a surgir. A infra-estrutura urbana é fator preponderante para esse acontecimento. Por exemplo, a construção da ponte Herćlio Luz e mais tarde da ponte Colombo Sales, construção e planejamento de aterros, estradas, duplicações, viadutos, para atender a necessidade da demanda populacional como também de turistas. Também a chegada de empresas como a ELETROSUL e a fundação da Universidade Federal de Santa Catarina em meados da década de 70, expandiram os fluxos de moradores e visitantes na cidade.

A infra-estrutura turística depende de fatores como: infra-estrutura de acesso, infra-estrutura básica urbana, equipamentos turísticos, equipamentos de apoio (BARRETO, 1995). Os produtos e serviços turísticos disponíveis para consumo são considerados ofertas turísticas, e seu conjunto faz parte do sistema turístico. A hospedagem é um desses produtos incorporados ao sistema turístico.

\section{Sistemas de informação geográfica (SIG) como metodologia de pesquisa}

O Sistema de Informação Geográfica (SIG) é uma base de dados computacionais, que agrega informações espaciais e procedimentos computacionais, que permite organizar e manipular informações cartográficas de acordo com as necessidades de análise.

É um conjunto de tecnologias que realizam o tratamento computacional de dados georreferenciados, descrevendo-os quanto aos seus atributos, relações espaciais e provendo um método consistente para análise e consulta.

Conforme a aplicação e a abordagem utilizada, há diferentes formas de se caracterizar SIGs. Uma definição bastante abrangente é a de que o termo Sistema de Informação Geográfica caracteriza sistemas automatizados usados para armazenar, analisar e manipular dados geográficos, ou seja, dados que representam objetos e fenômenos em que a localização geográfica é inerente à informação e indispensável para analisá-la (CÂMARA et al, 1996).

Um registro de dados alfa numéricos associados a elementos gráficos de um mapa digital pode estar vinculado aos seus atributos e localização no mapa. Os bancos de dados são sistemas com estruturas regulares, geralmente em formas de tabelas, compostas por linhas (Records) e colunas (Fields), semelhantes a planilhas eletrônicas.

O SIG é uma importante ferramenta para tratar de assuntos geográficos e ambientais. Um conjunto de informações formuladas em mapeamentos, tabelas ou gráficos permitem diagnosticar informações específicas de uma região.

\section{Distribuição dos meios de hospedagem em Florianópolis}

Detalhou-se a distribuição dos meios de hospedagem na llha, através da utilização do sistema de informação geográfica (SIG). O mapa base do município de Florianópolis dividido em Unidades Espaciais de Planejamento (UEPs) foi utilizado para a distribuição dos dados. No software de geoprocessamento os dados foram referenciados geograficamente em relação à superfície terrestre segundo um sistema de coordenadas conhecidas. É uma base de dados digitais no qual um sistema de coordenada espacial comum é o meio primário de referência.

O mapeamento por regiões contendo o número total de estabelecimentos, leitos e UH's, em três anos base: 1980, 1994 e 2004 permitem análises e diagnósticos sobre a demanda turística em cada área e no município. 
O número de estabelecimentos existentes em uma determinada localidade possibilita verificar os locais de maior concentração dos meios de hospedagem. Já, o número de UH's, representa a quantidade de apartamentos, quartos ou suítes existentes nos meios de hospedagens. Também podem ser verificados os números de leitos, que representa o número de pessoas que um meio de hospedagem tem a capacidade de receber (FARIA, 2003). Estas quantificações permitem a análise de seu significado, como o adensamento ou ampliação de meios de hospedagem, aumento ou retração na demanda turística na localidade.

A digitalização da distribuição dos meios de hospedagem na llha foram agregados não por UEPs (Unidades Espaciais de Planejamento), mas sim, por regiões homogêneas para fazer um comparativo de dados entre os 3 anos escolhidos. As datas escolhidas são devido ao possível acesso e existência de dados relacionados ao tema. E as regiões homogêneas foram delimitadas pelo critério do indicador de produção de resíduos. Os roteiros da coleta de lixo em cada região sofrem constantes alterações de rota (espaço) e tempo, por causa do crescimento acelerado da população na llha.

O Mapa de Regiões Homogêneas (Mapa 01) apresenta 5 regiões homogêneas. $\bigcirc$ Continente não foi incluído em nenhuma região homogênea. Entretanto foi considerado no contexto das análises referentes aos meios de hospedagem.

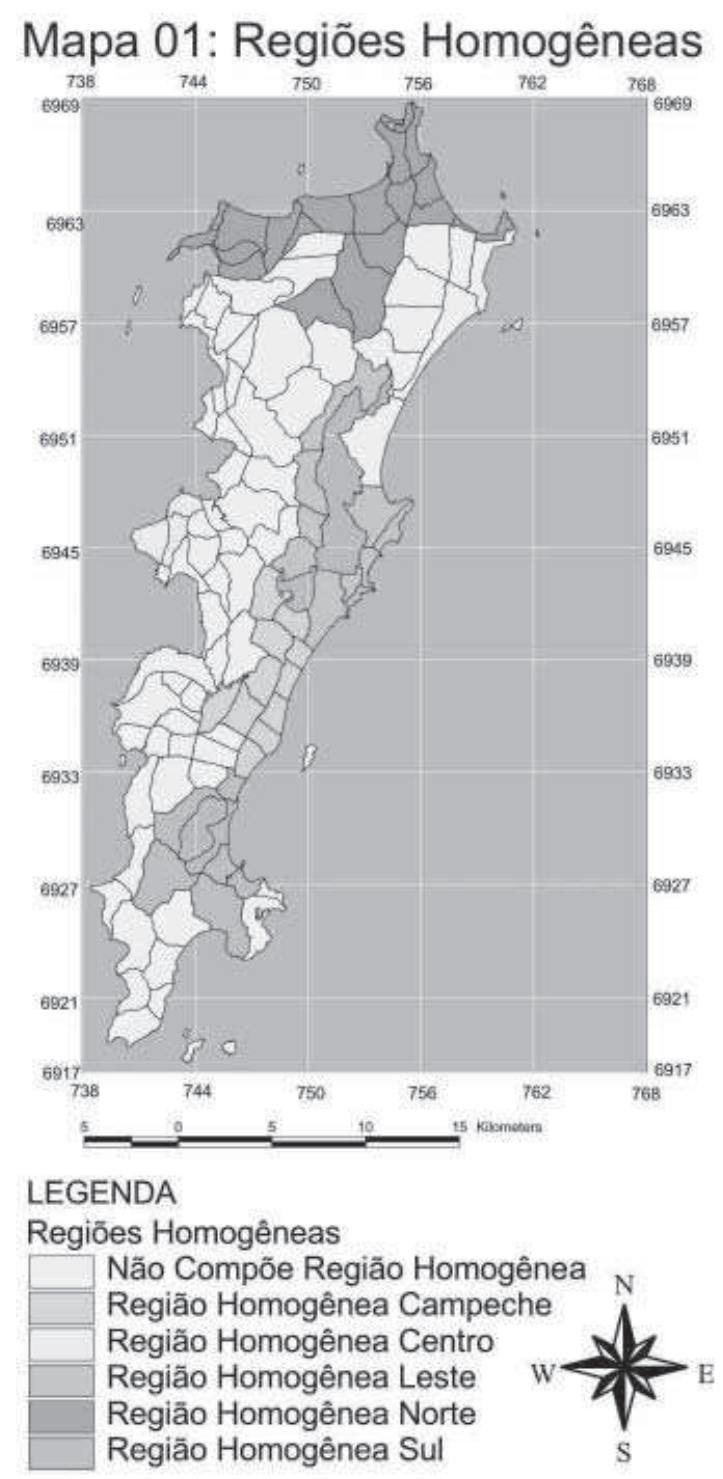

Fonte: Espíndola e Santiago, 2005. 


\section{Resultados e conclusões}

Ao analisar os dados de meios de hospedagem de referente ao ano de 1980 nota-se que a maior concentração de estabelecimentos (Mapa 02) é na Região Homogênea Centro e no Continente, respectivamente.

Já no ano de 1994 (Mapa 03) o crescimento é espantoso. Duas Regiões Homogêneas que antes não apareciam, Sul e Campeche, começam com alguns estabelecimentos. Provavelmente pequenos, pois os valores de UH's e Leitos não se destacam. Já as regiões Centro, Leste e, especialmente, Norte o crescimento é notável.

Mapa 02: Estabelecimentos 1980
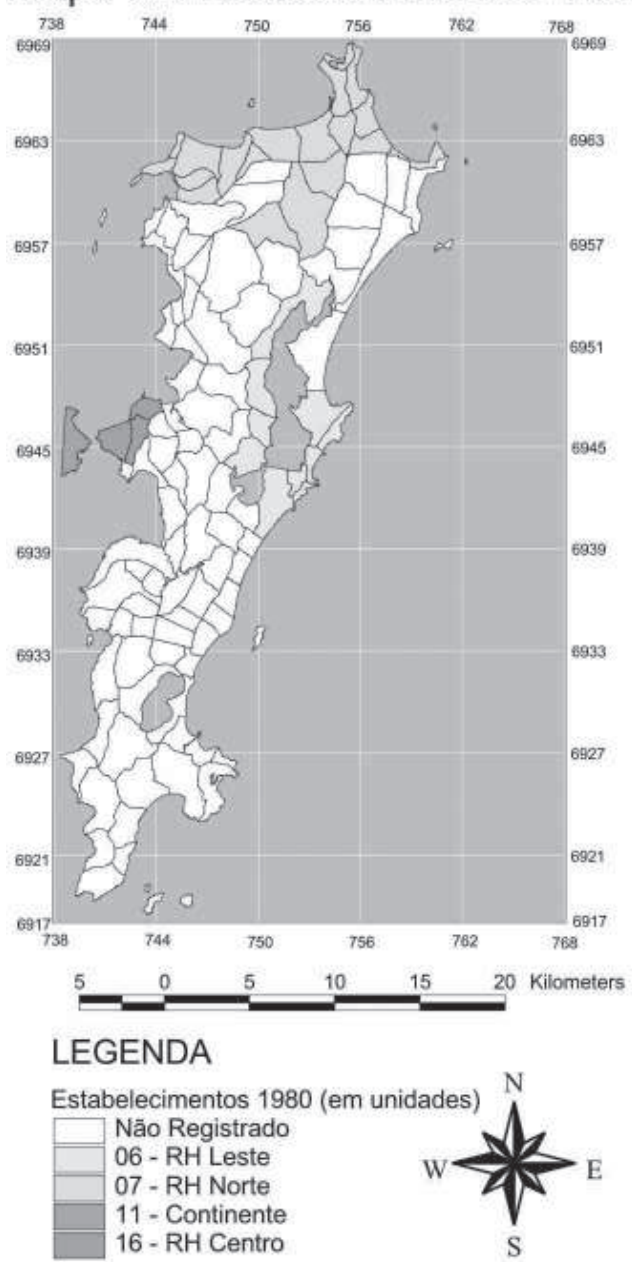

Fonte: Espindola e Santiago, 2005.

\section{Mapa 03: Estabelecimentos 1994}

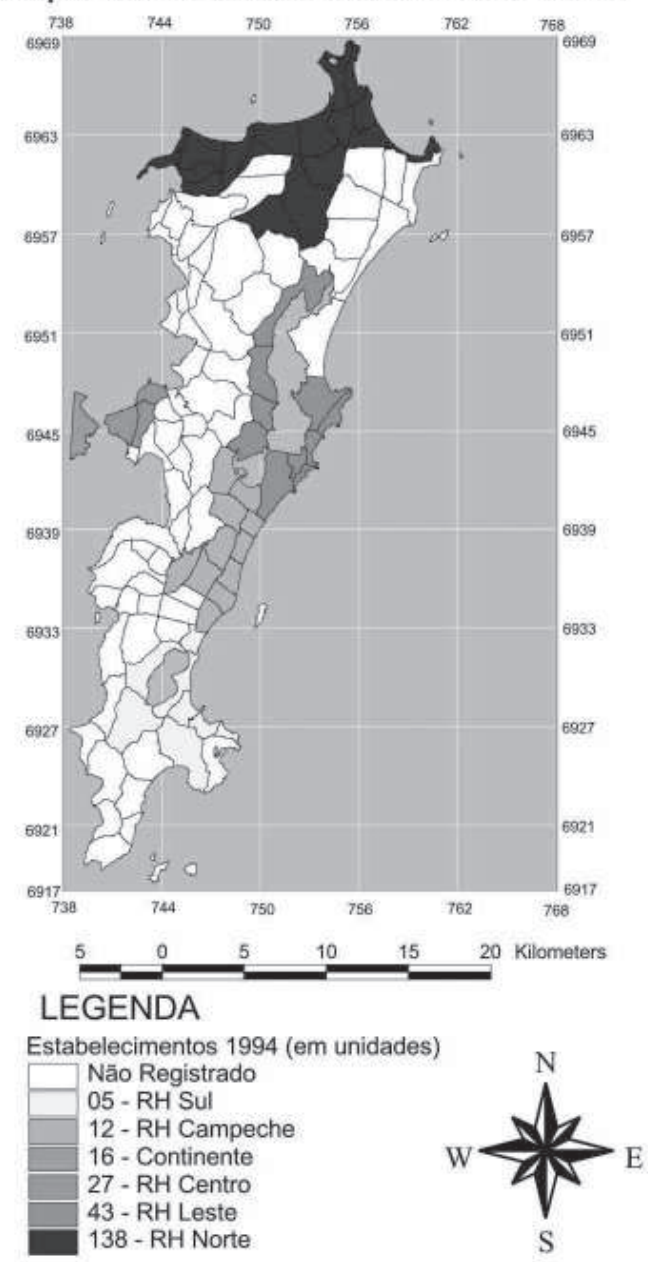

Fonte: Espíndola e Santiago, 2005.

Os dados relativos aos anos de 2003/2004 comprovam a estagnação de estabelecimentos hoteleiros (Mapa 04) na Região do Campeche e pouco aumento na Região Sul. Entretanto, nessas mesmas regiões o número aumenta pouco mais em relação aos leitos (Mapa 05) e UH's (Mapa 06). O Continente também ocorre poucas transformações nos valores. E a Região Centro não amplia número de estabelecimentos, apenas acresce os leitos e UH's, como se, provavelmente, se mantivessem os antigos estabelecimentos, e estes foram renovados para acolher mais hóspedes. Todavia, as demais regiões Leste e Norte o crescimento está cada vez mais impulsionado, em todos os aspectos. 


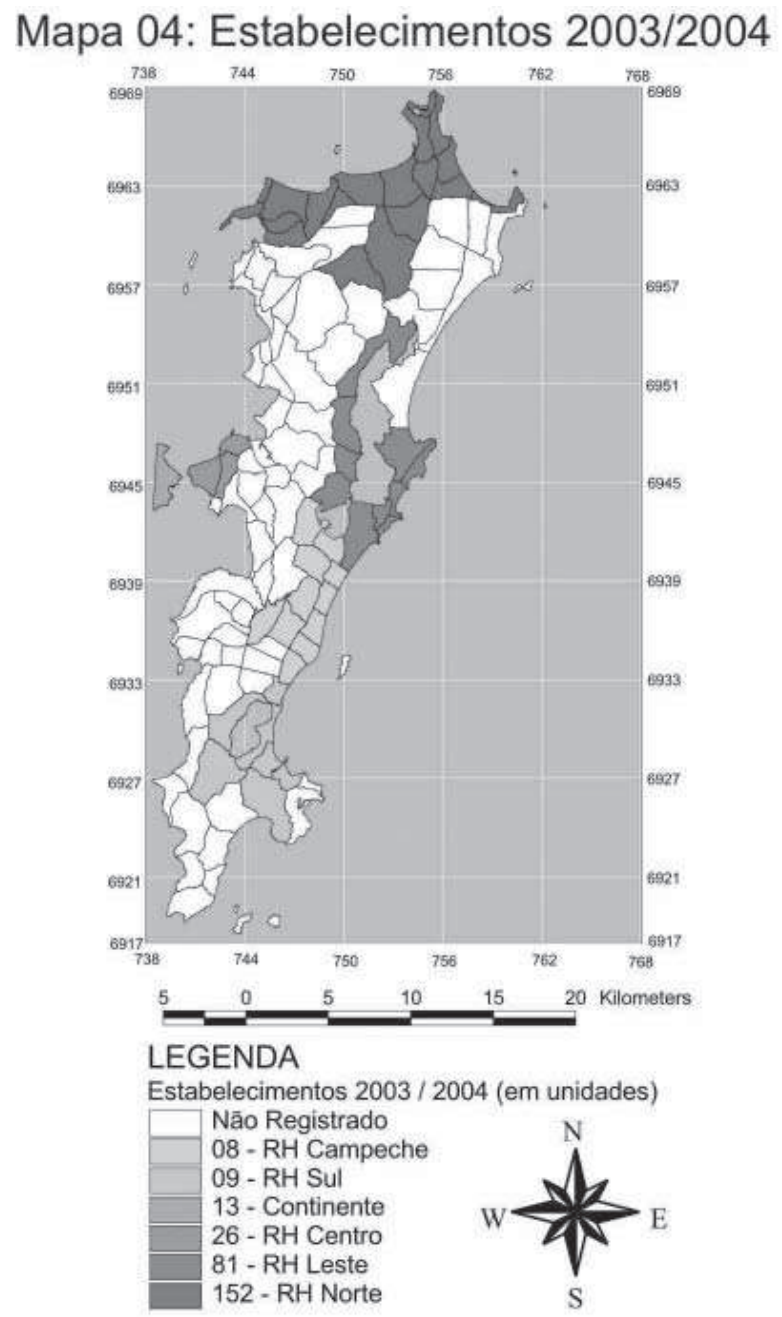

Fonte: Espíndola e Santiago, 2005.

De maneira geral, pode-se dizer que os estabelecimentos que no início se resumiam ao Continente e Região Centro, passaram a ocupar principalmente a Região Norte e Leste. E agora aponta para um crescimento nas Regiões Campeche e Sul. O mesmo acontece com os valores de UH's e Leitos, que tem maior destaque atualmente ainda na Região Norte, Centro e Leste.

No total o município apresenta uma soma de 289 estabelecimentos, 9531 UH's e 28722 leitos nos anos 2003/2004. Comparado com o valor de 581442 turistas, estimados pela SANTUR (2005), que vêm à cidade na alta temporada, mostra que além dos leitos dos hotéis e pousadas, existem outras alternativas de meios de hospedagens diferentes sendo utilizados atualmente. Entretanto, as casas ou apartamentos de aluguel são difíceis de contabilizar, pois nem todas são cadastradas.

Receber um excedente de turistas nas atuais condições fracas de infra-estrutura gera impactos ambientais e sociais marcantes. Atualmente o congestionamento no trânsito, a densidade da ocupação nas praias, o aumento de resíduos sólidos, as condições impróprias para banho de muitas praias, o aumento geral da polvição são fatos constantes durante as altas temporadas. Isso caracteriza um turismo de massa em Florianópolis, que compromete a perpetuação dessa prática na llha. Diluem no tempo o principal atrativo turístico: a paisagem natural, especialmente as praias.

O comprometimento da beleza natural é agravado por gananciosas intervenções antrópicas. Agentes preocupados investem na temporada de verão para garantir retorno monetário imediato. 
As obras, as construções, a infra-estrutura das cidades são orientadas e controladas por uma classe dominante. E a lentidão de propostas e evolução de atitudes é camuflada pelo "bombardeio" do marketing turístico que gera uma visão delirante de llha paradisíaca.

Mapa 05: Leitos 2003/2004
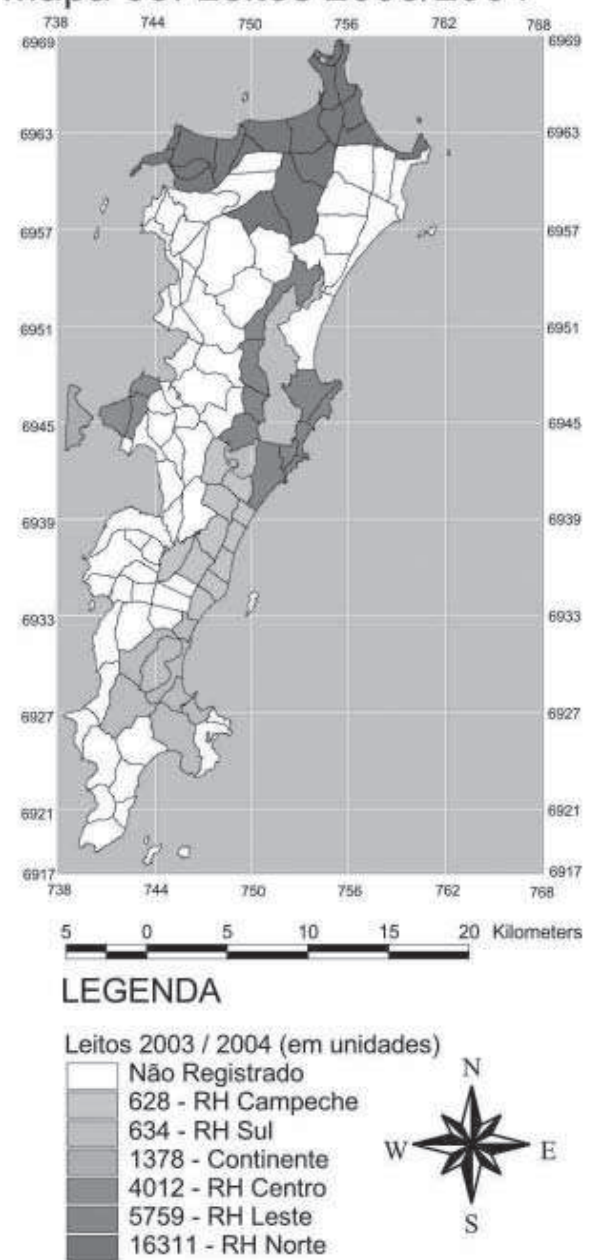

Fonte: Espíndola e Santiago, 2005.
Mapa 06: Uhs 2003/2004

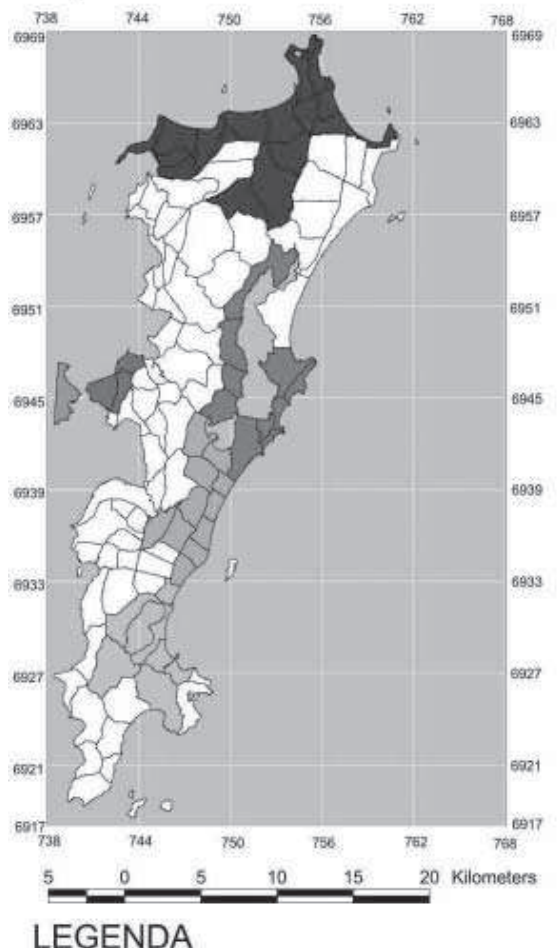

LEGENDA

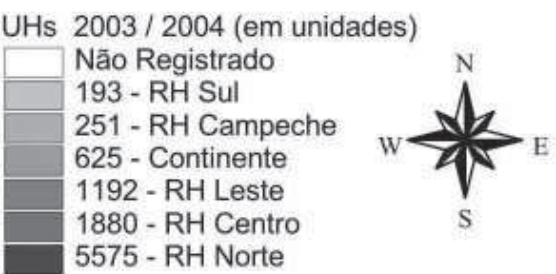

Fonte: Espindola e Santiago, 2005.

Verifica-se que uma leitura mais qualificada da transformação dos espaços urbanos nos sítios turísticos na llha de Santa Catarina é importante para apoiar e orientar políticas mais ajustadas à realidade. Através da elaboração de mapas temáticos que localizam estabelecimentos existentes, verificam-se as regiões sob maior demanda turística e o estágio de desenvolvimento turístico nas diversas áreas da Ilha, que possibilitam a manutenção de um turismo viável na llha de Santa Catarina, município de Florianópolis.

\section{Bibliografia}

BARRETO, Margarida. Manual de iniciação ao estudo do turismo. Papirus: Campinas, 1995.

CÂMARA, G. et al. Anatomia de sistemas de informação geográfica. Campinas: Instituto de Computação - UNICAMP, 1996. 
ESPÍNDOLA, Luciana da Rosa; SANTIAGO, Alina. Os efeitos perversos do turismo na llha de Santa Catarina. Relatório Final de Bolsa de Iniciação Científica. PIBIC / CNPq, UFSC, 2004.

Meios de hospedagem: Indicador da atividade turística na transformação do espaço urbano na Ilha de Santa Catarina. Relatório final de bolsa de iniciação científica. Santa Catarina: PIBIC/CNPq/UFSC, 2005.

FALCÃO, José Augusto Guedes. O turismo internacional e os mecanismo de circulação e transferência de renda. YÁZIGI, Eduardo; CARLOS, Ana Fani Alessandri; CRUZ, Rita de Cássia Ariza da. (Orgs.). In: Turismo: espaço, paisagem e cultura. São Paulo, Hucitec: 1996.

FARIA, Ana Lúcia. Modelo de análise para a gestão da atividade turística: O caso da llha de Santa Catarina, Florianópolis/SC. 2003. Projeto de tese submetido ao exame de qualificação para Doutorado. Programa de Pós-Graduação em Engenharia de Produção, Universidade Federal de Santa Catarina, Florianópolis, 2003.

HAFERMANN, Marília. Sustentabilidade e desenvolvimento turístico na llha de Santa Catarina. 2004. Tese (Doutorado em engenharia de Produção) - Universidade Federal de Santa Catarina, Centro Tecnológico, Florianópolis, 2004.

RANAURO, Marcio Lima. Sustentabilidade numa perspectiva endógena - Contribuição das "comunidades" no plano simbólico do desenvolvimento sustentável. Caderno virtual de turismo. Disponível em: <http://www.ivt-ri.net/caderno/>. Aceso em 24 jan. 2005.

RODRIGUES, Arlete Moysés. A produção e o consumo do espaço para o turismo e a problemática ambiental. In: YÁZIGI, Eduardo; CARLOS, Ana Fani Alessandri; CRUZ, Rita de Cássia Ariza da. (Orgs.). Turismo: Espaço, paisagem e cultura. São Paulo: Hucitec, 1996.

SANTOS, Fabíola Martins dos. Análise histórico-espacial do desenvolvimento da indústria hoteleira no núcleo urbano de Florianópolis nas últimas três décadas. In: VIII ENCONTRO NACIONAL DE TURISMO DE BASE LOCAL, 2004, Curitiba.

SANTUR - Santa Catarina Turismo. Movimento estimado de turistas. Disponível em: <http://www.sol.sc.gov.br/santur>. Acesso em: 24 jun. 2005.

SIQUEIRA, Lauren Fernandes de. Trilhas interpretativas: Uma vertente responsável do (eco)turismo. Caderno Virtual de Turismo. Disponível em: <http://www.ivt-rj.net/caderno/>. Acesso em: 24 jan. 2005. 